\title{
Human motifs at Neolithic Tepe Baluch, north-east Iran
}

\author{
Hadi Sabori ${ }^{1}$, Mina Norouzi Khorasani ${ }^{2} \&$ Reza Bolandi $^{3}$
}

The start of sedentary farming and herding in the Middle East transformed social and economic organisation and reshaped ideological structures and artistic representations. Tepe Baluch is a Neolithic settlement on the Neyshabur Plain in north-east Iran. Amongst the ceramic material excavated at the site, one particular sherd is of great interest. It is decorated with two (possibly three) motifs in the form of human figures. For this date and region, such Neolithic iconography is rare, and this short article develops a comparative analysis to explore its significance.

The site of Baluch is located on the outskirts of village of Taqi Abad, $17.5 \mathrm{~km}$ west of the city of Nishapur in the province of Khorasan Razavi (E $58^{\circ} 36^{\prime} 28^{\prime \prime}$, N $36^{\circ} 18^{\prime}$ $35^{\prime \prime}$; Figure 1). Archaeological excavations were undertaken at the site in summer 2011, identifying Neolithic and Iron Age contexts (Garazhian 2011; Figure 2). On the basis of the available natural resources, it seems probable that the site was occupied seasonally (Garazhian 2013: 30).

During the excavations, a sherd of pottery with human motifs was discovered in layer 14 of trench 2 (Figure 3). The sherd is $80 \mathrm{~mm}$ in length, with an average thickness of $14 \mathrm{~mm}$, and is made of brownish buff paste with sand temper that seems inadequate for hightemperature uses. The sherd has a buff slip on both the internal and external surfaces, with painted dark-brown human motifs on the exterior. On comparative grounds, in terms of paste, the sherd should date to the Early Neolithic. This makes the presence of the human motifs unique in the region for this date (Garazhian 2011, 2013: 26).

The human motifs are depicted in a partial side view. Two of them are complete; a probable third figure is broken off at the edge of the sherd. The motifs omit any detail of the face, head and body. No clothing is suggested and the sex of the figures is not apparent. The two preserved figures hold up their open hands, and the legs are bent at the knee indicating movement. The dynamism and broad symmetry of the figures, moving in opposite directions, may indicate dance.

A number of researchers have studied human motifs on prehistoric pottery (e.g. DunnVaturi 2003; Gabbay 2003; Garfinkel 2003a). Joseph Garfinkel (2003b) has provided the

1 Department of Archaeology, Art University of Isfahan, Hakim Nezami Street, Isfahan, Iran (Email: hadisabori79@yahoo.com)

2 Department of Archaeology, University of Shahid Beheshti, Shahid Chamran Highway, Yemen Street, Shahid Shahriari Square, Daneshjo Boulevard, Tehran, Iran (Email: mnoruzi@gmail.com)

3 Department of Archaeology, University of Golestan, Shahid Kalantari Boulevard, Shahrak Shahriyar, Shahriyar 5 Street, Golestan, Iran (Email: rezabolandi@yahoo.com) 


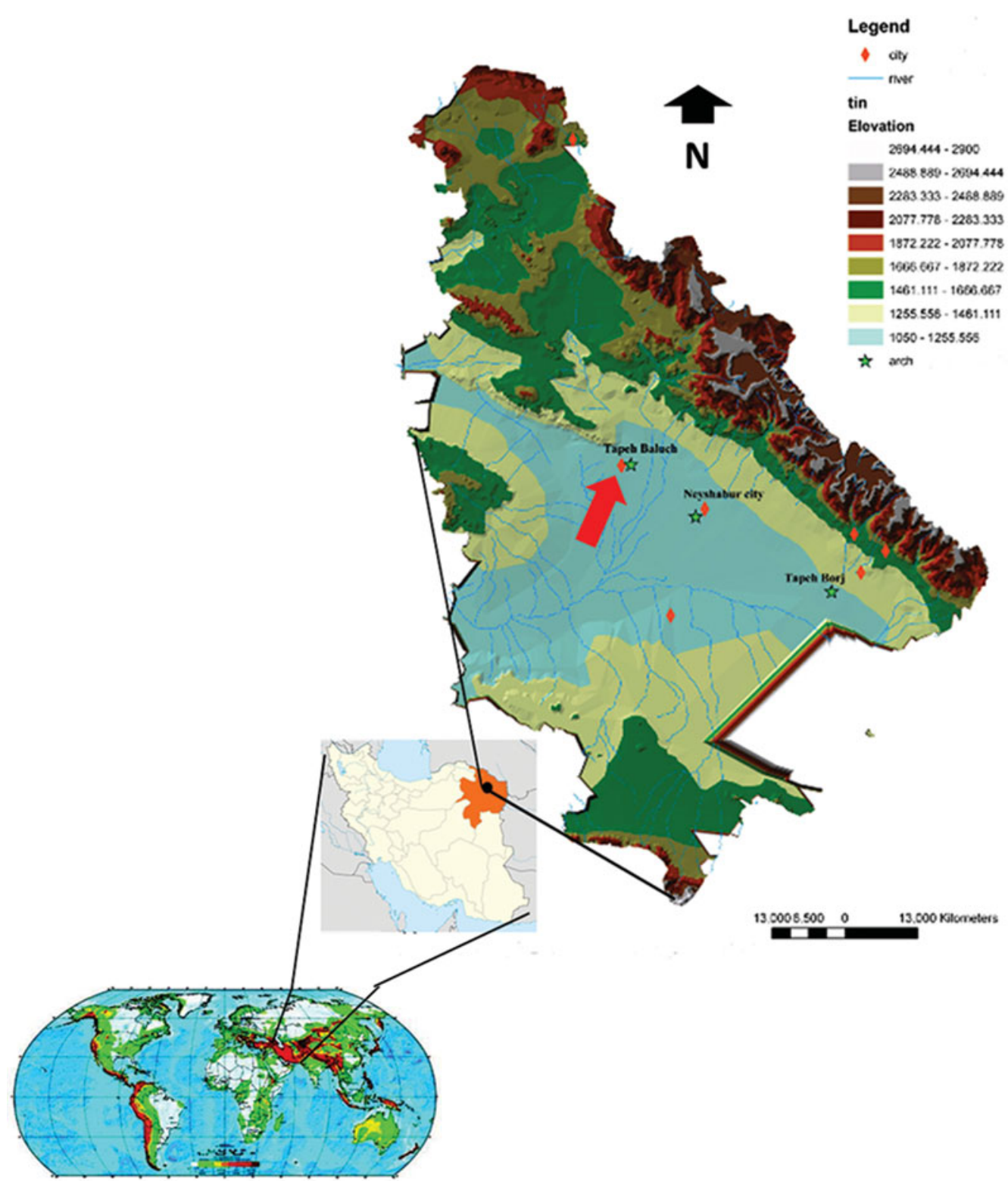

Figure 1. Location of Tepe Baluch in north-east Iran.

most comprehensive account with a global survey of human motifs on prehistoric pottery, placing special emphasis on the Middle East. His comparative study has also developed a typology of motifs based on body form and the style of depiction. Figures 4 and 5 show how the Baluch motifs relate to Garfinkel's typology.

Stylistically-without regard to geographic and chronological contexts-the posture of the human motifs of Tepe Baluch can be compared to the figures in the hunting (C) Antiquity Publications Ltd, 2017 


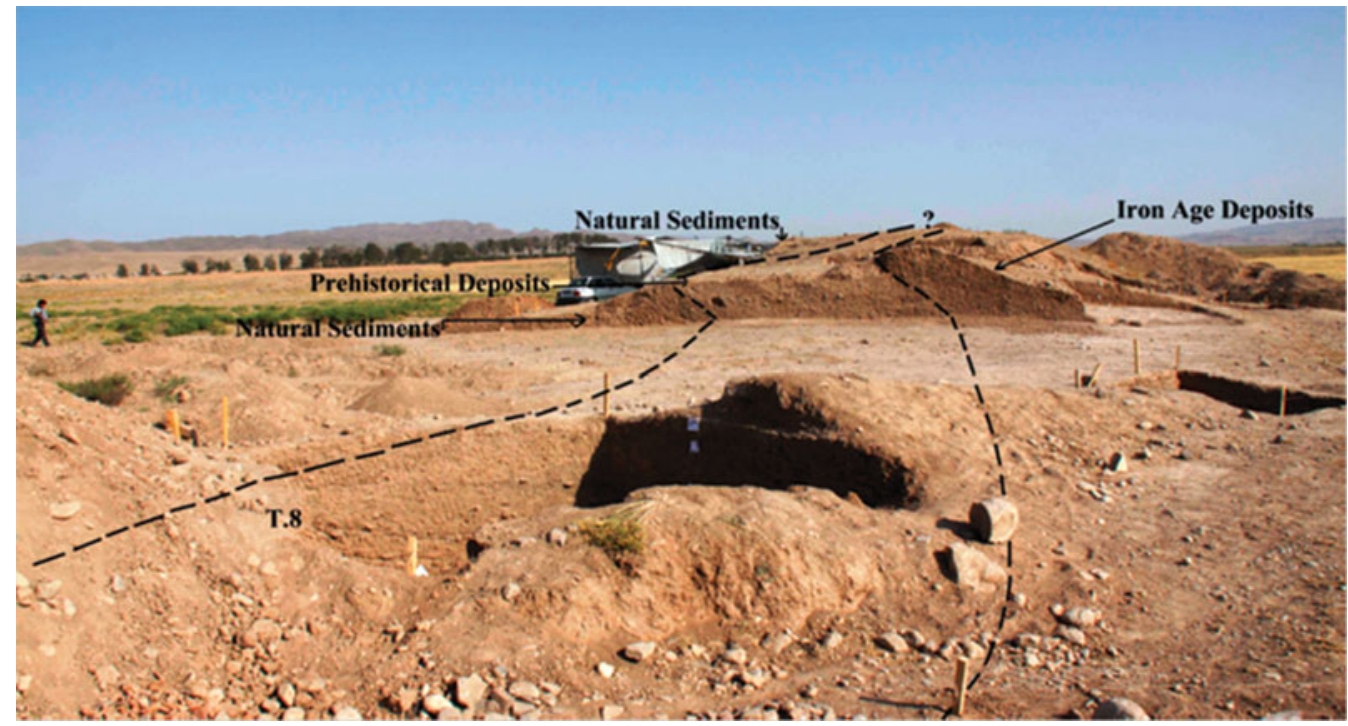

Figure 2. View of excavations at Tepe Baluch (Garazhian 2013: fig. 5).
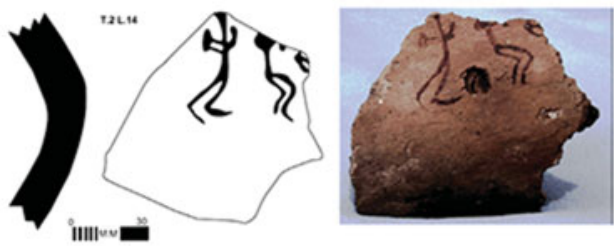

Figure 3. Human motifs on pottery sherd from Tepe Baluch (Garazhian 2013: fig. 18).

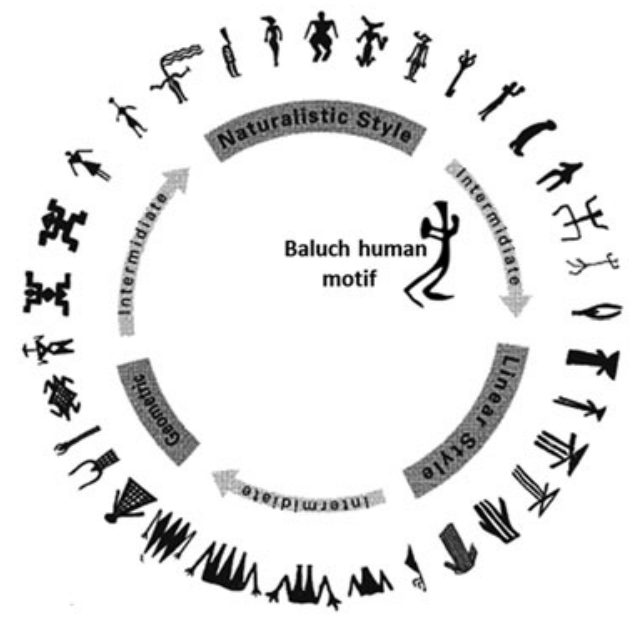

Figure 4. Diagram of human motifs and the position of the Baluch motifs within it (Garfinkel 2003a: fig. 8.8).

scenes from Çatalhöyük (Mellaart 1963: pls XLV \& LIV) (Figure 6a) and the human motifs of Tepe Gawra (Tobler 1950: pl. LXXVab) (Figure 6b), Sakje Gozu (Garstang et al. 1937: pl. XXV-15) (Figure 6c) and Sabi Abyad (Akkerman 1967: figs 21-40) (Figure 6d).

The emergence of human motifs and the representation of movement (dancing?) is documented at many archaeological sites across the Middle East, especially Iran, in the fourth and fifth millennia BC (Garfinkel 2003a: 85). The preliminary date of the 


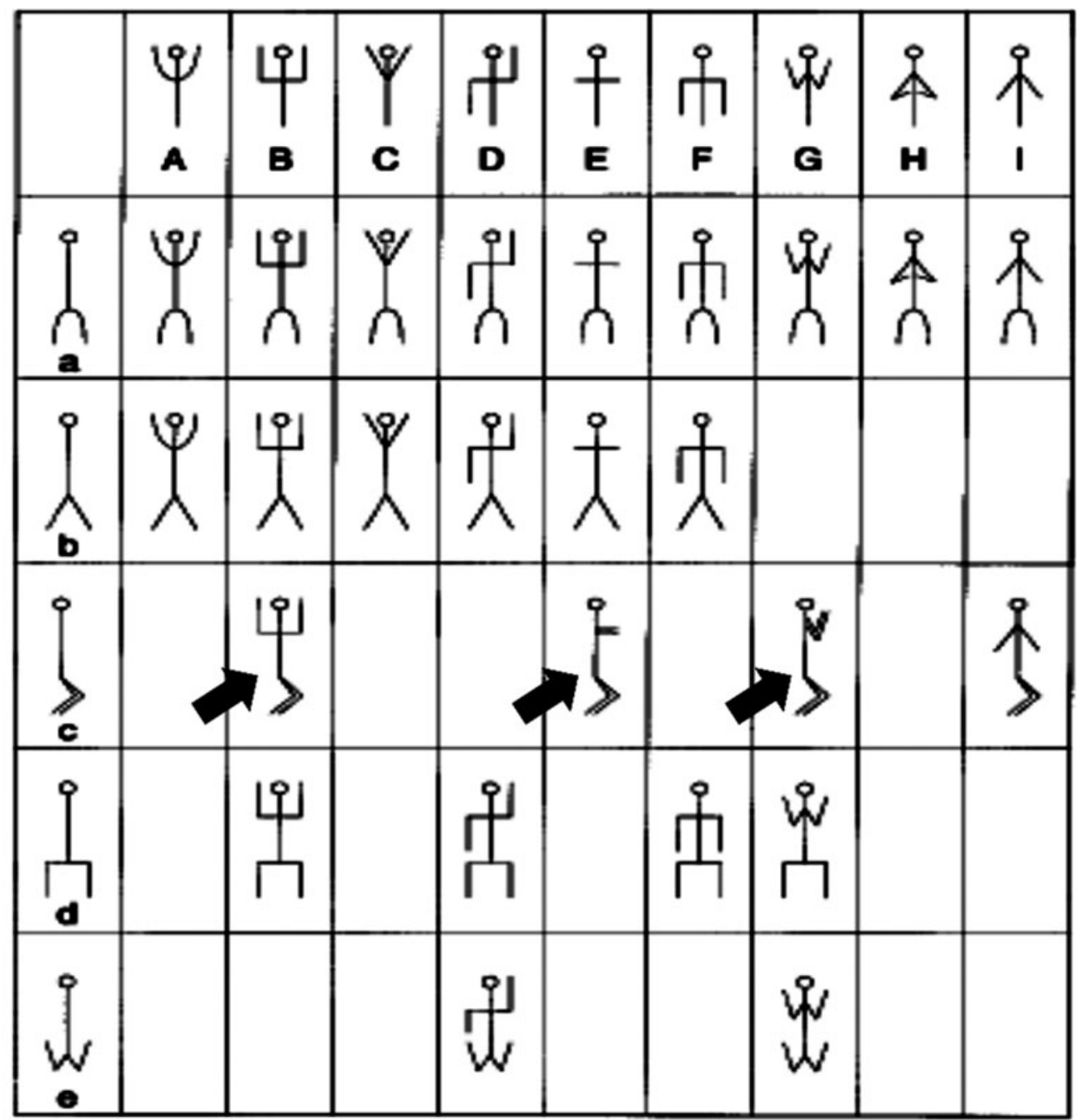

Figure 5. Table of human motifforms and the position of the Baluch motifs within it (Garfinkel 2003a: fig 2.3).

Tepe Baloch sherd with its human motifs is earlier: the seventh and eighth millennia BC.

The significance of the motifs may relate to ritual and ideological beliefs within this Early Neolithic society. The sherd was discovered in the context of a stone structure alongside the horns of a wild mammal (Garazhian 2013: fig. 21; Figure 3). The Khorasan practise a type of local fast-paced dance, which is comparable to the Tepe Baluch motifs, yet the use of ethnographic parallels across extremely long time scales to interpret and explain these motifs in terms of body form and movement of the hands and feet is, however, problematic. Regardless, this sherd points to the social and ideological complexity of the early farming societies of Iran.

(C) Antiquity Publications Ltd, 2017 


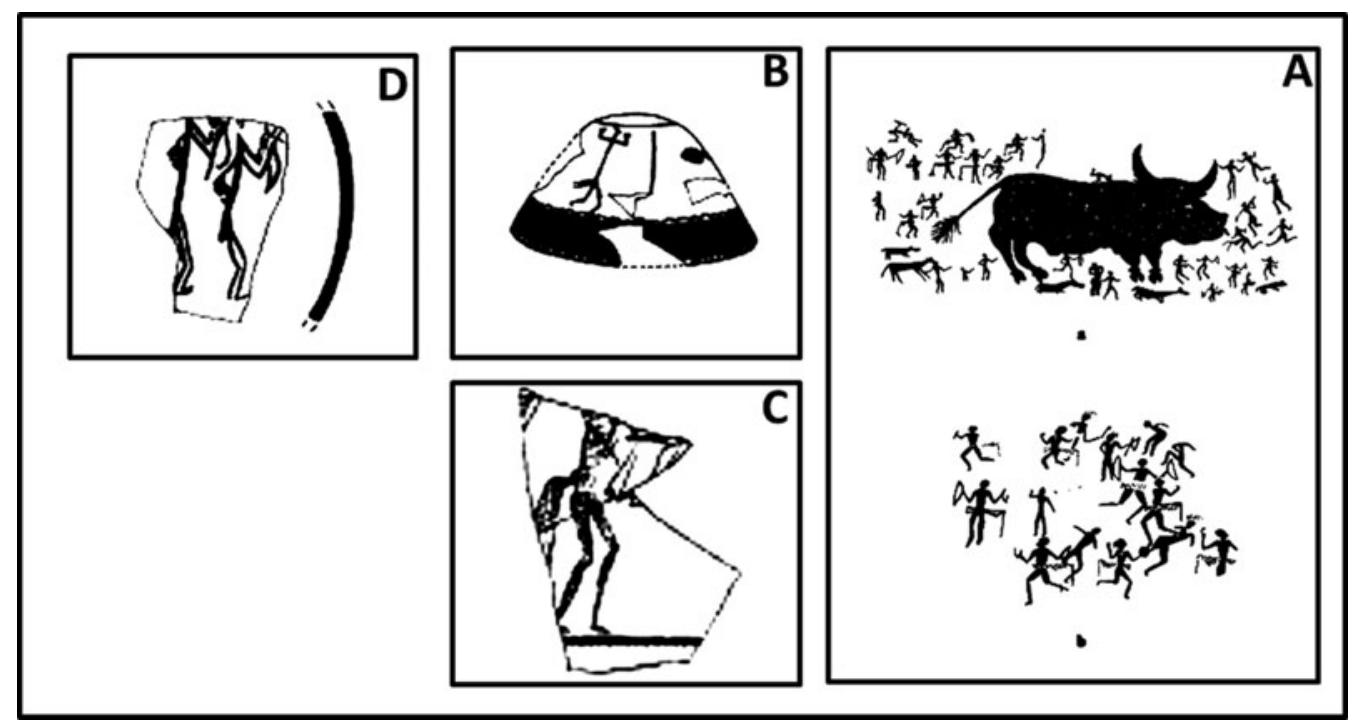

Figure 6. Human motifs comparable with the Baluch paintings.

\section{Acknowledgements}

We thanks H. Talai, O. Garazhian and Y. Garfinkel for their help and guidance.

\section{References}

Akkerman, P. 1967. Symbol and myth in prehistoric ceramic ornament. A survey of Persian art 14: 2914-29. London \& New York: Oxford University Press.

Dunn-Vaturi, A.E. 2003. Dancers in the Louvre: the Iranian and Cypriot collections. Near Eastern Archaeology 66: 106-10.

GabBay, U. 2003. Dance in textual sources from ancient Mesopotamia. Near Eastern Archaeology 66: 103-105.

Garfinkel, Y. 2003a. The earliest dancing scene in the Near East. Near Eastern Archaeology 66: 84-104.

- 2003b. Dancing at the dawn of agriculture. Austin: University of Texas Press.

Garazhian, O. 2011. Preliminary report of the first season of archaeological excavations in Tepe Baluch, Neyshabur. Unpublished manuscript, Archive of Iran Cultural Heritage, Handcrafts and Tourism Organization (in Persian).
- 2013. Recent excavations at Tapeh Baluch (Baluch Mound): a Neolithic site in Neyshabur Plain, NE Iran. Neo-Lithics 2: 20-31.

Garstang, J., W.J. Phythian-Adams \& V. Seton-Williams. 1937. Third report on the excavations at Sakji-Geuzi 1908-1911. Liverpool Annals of Archaeology and Anthropology 24: 119-40.

MellaART, J. 1963. Excavations at Çatal Hüyük, 1962: second preliminary report. Anatolian Studies 13: 43-103.

Tobler, A.J. 1950. Excavations at Tepe Gawra. Philadelphia: University of Pennsylvania. 